\title{
APPROACHES TO RADIATION GUIDELINES FOR SPACE TRAVEL
}

\author{
R. J. M. Fry
}

Biology Division, Oak Ridge National Laboratory, Oak Ridge, TN 37831 USA

Research sponsored by the Office of Health and Environmental Research,

U.S. Department of Energy under contract DE-AC05-840R21400 with the

Martin Marietta Energy Systems, Inc.

By acceptance of this article, the publisher or recipient acknowledges the $U . S$. Government's right to retain a nonexclusive, royalty-free license in and
to any copyright covering the article.

\section{DISCLAIMER}

This report was prepared as an account of work sponsored by an agency of the United States Government. Neither the United States Government nor any agency thereof, nor any of their employees, makes any warranty, express or implied, or assumes any legal liability or responsibility for the accuracy, completeness, or usefuiness of any information, apparatus, product, or process disclosed, or represents that its use would not infringe privately owned rights. Reference herein to any specific commercial product, process, or service by trade name, trademark, manufacturer, or otherwise does not necessarily constitute or imply its endorsement, recommendation, or favoring by the United States Government or any agency thereof. The views and opinions of authors expressed herein do not necessarily state or reflect those of the United States Government or any agency thereof. 
ABSTRACT

There are obvious risks in space travel that have loomed larger than any risk from radiation. Nevertheless, NASA has maintained a radiation program that has involved maintenance of records of radiation exposure, and planning so that the astronauts' exposures are kept as low as possible, and not just within the current guidelines. These guidelines are being reexamined currentIy by NCRP Committee 75 because new information is available, for example, risk estimates for radiation-induced cancer and about the effects of HZE particles. Furthermore, no estimates of risk or recommendations were made for women in 1970 and must now be considered.

The current career limit is 400 rem. The appropriateness of this IImit and its basis are being examined as well as the limits for specific organs. There is now considerably more information about age-dependency for radiation and this will be taken into account. In 1973 a committee of the National Research Council made a separate study of HZE particle effects and it was concluded that the attendant risks did not pose a hazard for low jnclination near-earth orbit missions. Since that time work has been carried out on the so-called microlesions caused by HZE particles and on the relative carcinogenic effect of heavy ions, including iron. A remaining question is whether the fluence of HZE particles could reach levels of concern in missions under consideration. Finally, it is the intention of the committee to indicate clearly the areas requiring further research. 
INTRODUCTION

The National Council on Radiation Protection set up a committee in 1983 to reexamine the effects of radiation exposure received in space activities. This paper is an account of the compittee's current approach to this task. This progress report is my impression of the task at hand and how It will be carried out, however, much of the material presented has been supplied by my colleagues on the committee and its advisors and consultants.

Since the National Academy of Sciences Panel examined the effects of radiation in space in 1970 , there have been considerable increases in the data from humans exposed to radiation and the approach to risk estimates has become more sophisticated.

There is now a body of Information about the radiation enviroment that have been and will be encountered in the future with actual exposure histories for astronauts. Trere is also more, though not sufficient Information about HZE particles. For these reasons, and the fact that women have Joined the ranks of space workers and more people will be involved in protracted missions it is timely to review recommendations for radiation exposure limits.

The assessment of radiation risks in space, dates back to 1961 when an ad hoc working group was set up by the Space Science Board of the National Acadewy of Sciences. This group was reconstituted 3 years later

* J. D. Bolce, V. R. Bond, S. Curtis, R. J. M. Fry, D. Grahn, W. X. Sinclair, J. B. Storer, P. Todd, Ex Officio - D. S. Nachtwey, Advisors: E. V. Benton, S. Fahn and B. Worgul, Consultants: E. J. Ainsworth, E. L. Alpen, J. Lett, E. G. Stassinopoulos and C. A. Tobias. 
and proceeded to make the first full systematic examination of the scientific and philosophical bases for establishing radiation protection criteria for manned space flights. ${ }^{1}$ Thus, when the Radiobiological Advisory Panel of the Space Science Board's Committee on Space Medicine was requested to formulate radiation protection guides there was both an accepted approach and some quantitative data on which to base risk estimates. It was realized that any recommendations would be "tentative" but should be useful to the designers of manned space vehicles and to the planners of manned missions. There was concern about keeping any recommendations in perspective since it was clear that the risks of leaving earth and travel in space, at that time, were far from negligible and in comparison radiation risks were not a first order problem. This perception proved to be prescient since radiation exposures up to now have been low, and sadly the risks associated with training such as flying and other accidents have taken their toll. On the other hand, the Panel looked to the future and considerid the possible effects of protracted radiation exposure that would be involved in inter-planetary missions and space stations. It was the concern of not knowing all the determinants required for a risk-benefit analysis that encouraged the Panel to adopt the concept of reference risk - "...it seems reasonable to recommend a primary reference risk that may be used as a point of normalization for plans and operations involving different numbers of personnel different risk-versus-gain evaluations, and different degrees of operational complexity. $n^{2}$

This philosophy was a continuation of the Panel's position in 1967 that rradiation-protection aspects of each type of manned space operation should be considered individually in context with a risk-versus-gain 
philosophy and the other risks inherent in the operation" and that the Panel had neither competency nor responsibility to evaluate the gain or benefit but should evaluate potential radiation risk in probabilistic terms.

The Panel considered radiation effects under three main headings: genetic effects, early effects and late effects. 2 The somatic effects, were considered of greatest concern, and were divided arbitrarily into early, or those up to 60 days, and late effects. The concern with early effects was the possibility of impairment of performance that might threaten the completion of the mission. It was recognized that dose and dose rates that could cause the dose and dose rate-dependent threshold effects would occur only if a large solar particle event (SPE) was encountered. Although nonspecific life shortening was still considered a late effect in 1970 it was appreciated that cancer was the somatic late effect of concern, and $r i s k$ of cancer should be the foundation of a recommendation for career exposure Iimits.

The Panel proposed the primary reference risk should correspond to an added probability of radiation-induced neoplasia over a period of about 20 years equal to the natural probability for the specific population vader consideration. The population under consideration consisted of men that would begin their careers between 30-35 years of age. In brief, it was determined from the data available at that time that 400 rem would be the doubling dose for the specific age group.

Based on the National Academy of Sciences recommendation, the Johnson Space Center Radiations Panel set permissible radiation exposure limits that have been adopted by the NASA administration (Table 1). NASA 
Table 1. Suggested Exposure Limits and Exposure Accumulation Rate Constraints for Unit Reference Risk Conditions.

\begin{tabular}{|c|c|c|c|c|c|}
\hline \multirow[b]{2}{*}{ Constraint } & \multicolumn{5}{|c|}{ Anclilary Reference Risiks } \\
\hline & $\begin{array}{l}\text { Primary } \\
\text { Reference Risk } \\
(\text { rem at } 5 \mathrm{~cm} \text { ) }\end{array}$ & $\begin{array}{l}\text { Bone Marrow } \\
(\text { rem at } 5 \mathrm{~cm})\end{array}$ & $\begin{array}{l}\text { Skin } \\
\text { (rem aí } 0.1 \mathrm{~mm})\end{array}$ & $\begin{array}{l}\text { Ocular Lens } \\
\text { (rem at } 3 \mathrm{~mm} \text { ) }\end{array}$ & $\begin{array}{l}\text { Testes } \\
\text { (rem at } 3 \mathrm{~cm} \text { ) }\end{array}$ \\
\hline 1-year average daily rate & & 0.2 & 0.6 & 0.3 & 0.1 \\
\hline 30-day maximum & & 25 & 75 & 37 & 13 \\
\hline Quarterly maximum ${ }^{\mathrm{a}}$ & & 35 & 105 & 52 & 18 \\
\hline Yearly maximum & & 75 & 225 & 112 & 38 \\
\hline Career limit & 400 & 400 & 1200 & 600 & 200 \\
\hline
\end{tabular}

a May be allowed for two consecutive quarters followed by 6 months of restriction from further exposure to maintain yearly limits. 
maintains a radiation program that involves: (a) prediction of expected doses for each flight, (b) maintenance of exposure records including medical exposures, (c) distribution of radiation exposures over each of the astronaut's career in order to keep exposures as low as possible (an attitude consistent with the ALARA principle, (d) measurement of radiation doses from various sources, (e) making every effort to prevent astronaut's exposure exceeding the limits recommended in the current guidelines. None of the astronauts has incurred more than a small fraction of the exposure limits. In fact, for most of the astronauts the radiation exposure in space are no greater than the exposure they have received from medical diagnostic procedures.

The radiation exposures have been low because most of the missions have been at low altitudes and favorable inclinations and short in duration. 3 The missions in outer space have been blessed by an absence of solar particle events.

The NCRP committee is reexamining the current guidelines to see what modifications might be made in the light of new data about cancer, and so-called non stochastic risks, with special attention to providing new recommendations about exposure of women. Priority will be given to the potertial risks that occupation of stations at different altitudes and inclinations will present.

In order to focus our examination of the radiation effects in space we have chosen four representative missions (Tables 2, 4,5 and 6). These examples are not, of course, likely to be precise representatives of the actual missions but they help to illustrate the range of doses, and the qualities of radiations that will be encountered. 
In the case of the proposed space station at $500 \mathrm{kl}$. in $28-1 / 2^{\circ}$ orbit, now in the planning stage, our scenario is probably close to what will happen.

Most of the radiation dose will be due to traversals through the part of geomagnetically trapped proton or Inner Van Allen Belt known as the South Atlantic Anomaly. There will also be small contributions to the total dose from energetic electrons of the outer belt and also galactic cosmic radiation. The doses shown in Tables $2,3,4$ and 5 are based on the assumption that the space station stiucture will have a thickness of about $2 \mathrm{~g} / \mathrm{cm}^{2}$ of aluminum-equivalent material.

Table 2

Space Station A

Alticude: $500 \mathrm{~km}, \quad$ Orbit: $28-1 / 2^{\circ}$

Main Source of Radiation: Inner Van Allen Belt

(South Atlantic Anomaly)

Dther Sources of Radiation: Solar particle events

Radiation Quality: Protons (assumed $Q$ value of 1.2)

Estimated Doses for 90-day Mission:

Skin: $\quad 10 \mathrm{rad}(0.1 \mathrm{~Gy})$

Bone Marrow: $8.6 \mathrm{rad}(0.86 \mathrm{~Gy})$ 
Since the space station will be o:biting for an indefinite period SPEs, and therefore, solar cosmic radiation will almost certainly occur at some time. However, the dose, even with a very iarge event, will be reduced because of the protection of the gecmagnetic field. In Table 3 the doses predicted by Hardy and co-workers ${ }^{4}$ for a SPE of the magnitude of the 1972 event that would be incurred inside a vehicle at the $28-1 / 2^{\circ}$ and polar orbits. It can be seen that the dose to the marrow at $28-1 / 2^{\circ}$ orbit is not great, and not more than one exposure to a major SPE is likely to occcur in a career. Thus the contribution to a career dose should be small.

\section{Table 3}

\section{Doses in Space Station} Due to Solar Particle Event

(Hardy et al.)

Orbit

(degrees)

$28-1 / 2^{\circ}$

$90^{\circ}$
Dose (rem)

Skin

Bone Marrow

30

2

280

Based on the radiation levels of the 1972 SPE.

In the consideration of the radiation that will be experienced in each type of mission we will include an extra vehicular activity (EVA). In 
the case of the $28-1 / 2^{\circ}$ orbit a 6 -hour EVA, that involvt $z$ transits through the South Atlantic Anomaly, could add 3 or 4 rads to the skin dose. The second representative mission (Table 4) is the space station in polar orbit. Although at the same altitude as the Space Station the 28-1/2 ${ }^{\circ}$ orbit there will be a different radiation environment. Because of the form of the Van Allen Belts there is much less geomagnetic shielding at the pole. Thus in a polar orbit the radiation environment is qualitatively similar but quantitatively different from free space radiation.

\section{Table 4 \\ Space Station B}

Altitude: $500 \mathrm{~km}$ Orbit: $90^{\circ}$

Sources , R Radiation: 1) Horns of radiation belts

2) Galactic cosmic rays

3)

Radiation Quality: Electrons: radiation belts

Galactic Cosmic Rays: protons, alpha particles, and heavy ions

Estimated Doses for 90-day Missions:

Skin Bone Marrow 


\section{Discussion of Radiation Hazards to Low Earth Orbit Stations}

Although workers on the space station in $28-1 / 2^{\circ}$ orbit will be in space for relatively long periods the accumulated dose for, say 10 missions, will be considerably lower than the current NASA career limits and the maximum permissible doses for the working lifetime of terrestrial workers. However, if the missions are over about 52 days, the annual dose will exceed 5 rads per year.

In the case of workers in a station in polar orbit, although the radiation environment is clearly less desirable and may entail some differences in mission planning, than the $28-1 / 2^{\circ}$ orbit, it should not constitute a major problem. Solar particle events are of real concern (Table 3) but a significant reduction in the exposure of the crew can be obtained by maneuvering the space station.

The contribution of galactic cosmic rays to the dose inereases as the free space radiation environment is approached. Heavy ions are a small component of the total galactic radiation but their effect is much greater than the lower LET radiations that make up almost all of the dose.

In conclusion it appears that the space station at $28-1 / 2^{\circ}$ orbit presents no unknown risks and that any one worker could carry out a reasonable number of missions within career limits that were based on acceptable risks. In the case of polar orbits a worker's radiation history and therefore his career will be influenced much more by whether or not she or he is exposed to SPES.

We are not considering the greatly increased hazard that a nuclear explosion will entail. The radiation injected iato magnetosphere by such an explosion could increase the trapped electrons for a very long time and 
therefore the dose rate of radiation in the radiation belts.

Quter Space Missions

In outer space the radiation dose rates are considerably higher than experienced in low earth orbits. However, missions, such as in the Apollo program, involving flight through the trapped radiation in the Van Allen belts and time in the free space radiation environment did not. expose astronauts to levels near the recommended limits. But exposure to higher total doses will come as the duration of the missions is extended and the hazaris have been reviewed recently. 5 Some of the characteristics of misstons in geosynchronous orbit (GEO) are shown in Table 5 .

Table 5

Space Station C

Altitude: $36,000 \mathrm{~km} \quad$ Orbit: Equatorial

Sources of Radiation:

1) Trapped radiation: electrons

2) Secondary radiation: Bremsstrahlung

3) Galactic Cosmic rays

4) Transit through Van Allen Belts: Protons and Electrons

Estimated dosas for 90-day mission:

Skin: $42 \mathrm{rads}(0.42 \mathrm{~Gy}) \quad$ Bone Marrow: $33 \mathrm{rads}(0.33 \mathrm{~Gy})$ 
The confidence limits in the estimated doses incurred in flights in GEO are considerably broader than for missons in LEO because the trapped radiation enviroment at the GEO altitude fluctuates markedly.

Estimates of risk of excess cancer mortality have been made by two Commit tees for activities in $\mathrm{GEO}^{6,7}$ concerning the hazards involved in putting a Satellite Power System in place. Not surpisingly the estimates of risk varied by about a factor of 3 . The estimates for excess cancer mortality risk for males carrying out ten 90-day missions ranged from $6 \%^{6}$ to $20 \% .7$ It is in these high altitude missions beyond the shielding of the magnetosphere that the "ull impact of the galactic cosmic rays and on occasions solar flares will be felt but the estimates of risks made by the committees for workers on the Satelifte Power System did not take into accoui sadiation from SFEs. Although predictions of these events and methods of protection may recuce the doses incurred, SPEs represent a major concern for stations in GEO.

We selected a lunar mission as the fourth of the representative missions (Table 6 ) but it will not be discussed here since the contribution of the many factors that will influence the doses have not been evaluated. For example, with any extended sojourn on the moon's surface it is expected that there will be provision for a shielded area where at least part of the time would be spent. 


\author{
Table 6 \\ Lunar Mission \\ Two Days Leo - Moon \\ 90 Days on Lunar Surface \\ Major Sources of Radiation: \\ 1. Van Allen Radiation \\ Belts During Transit \\ 2. Galactic Cosmic Rays \\ 3. Solar Cosmic Rays (SPE)
}

\title{
Discussion of Radiation Hazards in Outer Space Missions
}

It is with the extended uissions beyond the magnetosphere that radiation hazards become of major concern, in part, due to the possibility of solar particle events and also to the uncertainty of the importance of HZE particles.

Acute Effects - Exposure to a very large SPE in outer space could cause acute radiation effects. While the dose rate may rise rapidly from the onset of a SPE it is considered likely that there will be sufficient time to take some precautions, such as shelter, before doses of the order 
of $150 \mathrm{rem}(.15 \mathrm{sv})$ are received. It is unlikely that acute effects that are difficult to manage will occur but exposure to tens of rads of radiation at relatively high dose rates will increase the probability of both subsequent cancer and possibly noncancerous lesions. Such dose leveis would be of especial concern if the crew or space workers were of reproductive age.

Theoretically chemical radioprotectors are an attractive idea for protection against the effects of events such as SPEs but, unfortunately those that are effective are also prone to produce nausea and vomiting. In the foreseeable suture physical methods of protection offer the best hope, except in the case of heavy ions. Since missions in outer space for extended periods are unlikely to take place for some years it is possible that the search for suitable chemical radioprotectors will by then have succeeded.

HZE Particle Radiation - There are two concerns about heavy ions. First, whether the so-called microlesions that may result from the traversal of a heavy ion pose a special risk to tissues that cannot be predicted from our store of information about the effects of Iow- and high-LET radiations. Second, it has become clear that heavy ions are carcinogenic but their relative eff zctiveness is not known precisely. This lack of knowledge hinders an appropriate weighting of their contribution to the total cancer risk. Since the fluence of HZE particles is relatively Iow their relative contribution to risk depends on how high is the RBE for cancer induction.

Data on the effects of HZE particles have accumulated slowly since the subject was reviewed by the Radiobiological Advisory Panel of the 
National Research Council. ${ }^{8}$ The majority of work has been carried out on acute and noncancer late effects on tissues and organs, $9-13$ Unfortunately, not many studies have been on the effects of ${ }^{56} \mathrm{Fe}$ the most prevalent particle of $z>14$ and no studies have been reported that answer the question of whether small but vital cell populations, such as CNS nuclei and centers, can be compromised by exposure to fluences that might occur in space. The concept of the microlesion has gained some support from the work of Nelson and Tobias ${ }^{11}$ but we are no closer to resolving unequivocally the lingering question of whether HZE particles in space pose a special and significant hazard.

It can be seen from Figure 1 that $56_{\mathrm{Fe}}$ particles are markedly more carcinogenic than low-LET radiation, particularly at very low doses. The slope of the dose-response curve for the induction of tumors in this particular gland by $56_{\mathrm{Fe}}$ is about the sare as that for fission neutrons. It is thought that the RBEs for biological effects rise with increasing LET, reach a maximum at about $100 \mathrm{keV} / \mu \mathrm{m}$, and then decrease. In the case of tumorigenesis it appears possible from the results of our Initial studies that the RBE may remain high even with radiations with LET values in excess of $100 \mathrm{keV} / \mu \mathrm{m} .{ }^{14}$ I or protection purposes the cancer rates due to fission neutrons should provide a guideline but this needs confirmation.

In the LEO missions protons of various energies will be the major contributor to the total dose. There are no data for the induction of cancer by protons in humans and rot much for experimental animals. The U.S. Alr Force have had groups of Rhesus monkeys, that were exposed to doses ranging from 75 to 1055 rads and ranging from 32 to $2300 \mathrm{MeV}$, under 
study for many years. ${ }^{15}$ The cancer mortality, based on data pooled for the various energies, as a function of dose is not linear and excess mortality is noted at doses greater than 213 rads. ${ }^{16}$ Thus, the provisional selection of a quality factor of 1.2 for protons in the estimates of doses that may occur in persons on the Space Station in $28-1 / 2^{\circ}$ orbit appears reasonable but there is a need for more information about both carcinogenic and non-tumor effects of protons.

\section{Approach to Estimates of Cancer Risk}

There has been no time at which proposed estimates of the risk of cancer from exposure to radiation met with full agreement. Today, when the problem of risk prediction is being studied by more people with more incentives than ever is no exception. The complexity of the problem of risk estimation is illustrated by the length of the list of the factors involved (Table 7).

Since the subject of protection standards has been covered by Sinclair ${ }^{17}$ I shall only comment on a couple of aspects. Risk estimates for the effects of exposure in space is complicated by the fact that the radiations are of different qualities. In the case of LEO missions the use of a single quality factor may be appropriate but in outer space missions a method of adding individual risks from exposure to the main radiation qualities would be preferable. 
Table 7

Factors that Influence the Estimate of Risk or Radiation-Induced Cancer

Physical

Biological

Analytical

Radiation Quality

Dose

Dose Rate

Fractionation
Genetic Factors

Age

Sex

(b) Projection Models:

Choice of:

(a) Models for Dose-Response

Absolute Risk

Relative Risk

In terrestrial protection standards no account has been taken of the relationship of susceptibility to the age at exposure. The information about this relationship is still inadequate but it has become clear that in the case of breast cancer in women that the susceptibility for radiation induction decreases with age and women exposed at 45 years of age or older show no excess risk. 18

It is clear that a great deal more information is required about age-dependency but it is equally clear that the risks will depend on the age distribution of the space workers. For this reason we intend to estimate separately cancer risks for the following age groups: (a) 25-45 years, 35-55 years and 40-60 years and, of course, for both sexes. For 
each age group a 20 year career w.:th an equal number of missions will be considered.

Although the mortality from skin tumors (nonmelanoma) is negligible we will examine this risk in some detail because the doses to the skin in a career are likely to be considerably greater than for other tissues and It is becoming clear that exposures to ultraviolet radiation from the sun interact with ionizing radiation and increase the risk of skin cancer. 19 Counseling about exposure to sunlight for the space workers with skin types that are considered to be at high risk would appear to be sensible.

The National Research Council's Committee used a reference risk as the basis of the original recommendations about the radiation risks in space. 1 The phllosophical basis of risk hes teen discussed in Sinclair's paper 17 and the NCRP committes will have to decide whether some acceptable increase in mortality or incidence risk is the appropriate benchmark for recommending career and annual exposure limits. It seems obvious that the risks of cancer misi be put in perspective with the other risks of space travel and must be compared to the risks of other occupations.

In general, provision of career limits of exposure that restrict the possibility of excess cancer to low and acceptable levels automatically provide adequate protection irom other late effects. However, effects on the lens and on the ovary and testes will be included in our report. 
The Approaches to Consideration of Other Risks

\section{Cataract}

Since much of the radiation experienced in space may well be of relatively low energy special care has to be taken with the examination of risk to organs near the surface and therefore the risk for cataract will be examined in detail. There is an unfortunate lack of information about the induction of cataracts in humans by high-LET radiation. Patients treated with protons, helium and neutrons should in the future provide useful data. Until then we have to rely on animal studies. $12,20,21$

\section{Cenetic Risks}

We will indicate the genetic risks that result from exposure to radiation using the most recent estimates available. Two relevant changes are occurring since the original recommendations were made, namely, women are now crew members and at last some crew members are young and likely to reproduce. These facts will be taken into account in our recommendations and especially in detailing suggestions for counseling.

The number of space workers and crew that are of reproductive age will remain small and therefore the increase in the mutation burden of the human gene pool will be insignificant. Thus the problem of risk becomes a matter at the level of an individual rather than the population. The NCRP Committee will use the genetic risks set out in its forthcoming comprehensive document on radiation risks now in review. 


\section{Cenclusion}

There is work to be done in the experimental field to substantiate assumptions that must be made in the field of risk estimates. Nevertheless, despite the gaps in our knowledge about the precise doses that will be experlenced, especlally in outer space, and about the late effects of HZE particles, it will be possible to make recommendations about protection standards for workers in space with considerable confidence. The management of an individual radiation exposure by judicious spacing of missions or curtailing a career call always be used to add flexibility in limiting a lifetime radiation exposure to acceptable levels. The experience of the astronauts to date suggests that with certain precautions extended missions at the less benign altitudes can be carried out without excessive risk. An increase in the ability to predict SPEs would be a major step forward since the dose incurred in outer space from a large SPE could greatly outweigh the doses from other sources. 
References

1. Radiobiologica? Factors in Manned Space Flight. H. H. Langham (ed.). Report of Space Radiation Study Panel of the Life Sciences Committee. Space Science Board, National Academy of Sciences Washington, DC, 1967 .

2. W. H. Langham and D. Grahn. Radiation Protecticn Constraints, Guides and Constraints for Space - Mission and Vehicle - Design Studies Involving Nuclear Systems. Radiobiological Advisory Panel, Committee on Space Medicine Space Sciences Board, National Academy Press, Washington, DC, 1970.

3. E. V. Benton and R. P. Henke. In: Adv. Space Res., Ed. W. R. Holmquist. 4. A. Hardy. Personal comunication, 1984.

4. A. Hardy, R. Beever, W. Atwell. Personal communication, 1984.

5. M. C. Stauber, M. L. Rossi, E. G. Elassinopoulos. In: Proceedings of the 34 th Congress of International Astronomical Federation, Budapest, Hungary, 1983.

6. National Research Council. A report prepared by the Committee on Satellite Power Systems. National Academy Press, Washington, DC, 1981.

7. U. S. Department of Energy, DOE/ER0094, 1980.

8. Radiobiological Advisory Panel, Committee on Space Biology and Medicine, Space Science Bord, National Research Council. D. Grahn (ed.), National Academy of Sciences, Washington, DC, 1973.

9. J. T. Lett, E. J. Ainsworth and E. L. Alpen. In: Advances in Radiat. Biol. J. T. Lett and H. I. Adler (eds.), 10: 191-236, 1982.

10. P. Todd. In: Adv. Space Res., W. R. Holmquist (ed.), Vol. 3, No. 8, 
pp. 187-194, 1983.

11. A. C. Nelson and C. A. Tobias. In: Adv. Space Res., W. R. Holmquist (ed.), Vol. 3, No. 8, pp. 195-209, 1983.

12. A. B. Cox, E. J. Ainsworth, J, G. Jose, A. C. Lee and J. T. Lett. In: Adv. Space Res., W. R. Holmquist (ed.), Vol. 3, No. 8, pp. 211-219, 1983 .

13. D. S. Bergtold, A. B. Cox, C. M. Su and J. T. Lett. In: Adv. Space Res., W. R. Holmquist (ed.), Vol. 3, No. 8, pp. 221-229, 1983.

14. R. J. M. Ery, P. Powers-Risilus, E. L. Alper, E. J. Ainsworth and R. L. Ullrich. In: Adv. Space Res., W. R. Holmquist (ed.), Voi. 3, No. 8, pp. 241-248, 1983.

15. J. M. Krupp. Radiat. Res, 07: 244-251, 1976.

16. D. H. Hood. Personal communication, 1984.

17. W. K. Sincla1r. This volume, pp....

18. M. Tokunaga, C. E. Land, T. Yamamoto, M. Asano, S. Tokuoka, H. Ezaki, I. Nishimori and T. Fujikura. In: Radiation Carcinogenesis, Epidemiology and Biological Significance. J. D. Bolce, Jr., J. F. Fraumeni, Jr. (eds.), pp. 45-56, 1984.

19. R. E. Shore, R. E. Albert, M. Reed, N. Harley, and B. S. Pasternack. Radiat. Res, in press, 1984.

20. E. J. Ainsworth and J. G. Jose. Radiat. Res. 91: 371-372, 1982.

21. G. R. Merriam, Jr. and B. V. Worgul. C. Medvedorsky, M. Zaider and H. Rossi (eds.), Radiat. Res., in press, 1984. 


\section{Eigure Legend}

Elgure 1. Percent of tumors in Harderian glands as a function of dose of Iron particles at $600 \mathrm{MeV} / \mathrm{amu}$ in the plateau region of the Bragg Peak: $A-A$ and ${ }^{60}$ Co gamma rays: -4 . The percent of tumors is based on the fraction of the total no. of tumors/total no. of glands ( $2 x$ no. of mice). Multiple tumors were more frequent In the animals irradiated with Iron particles. 
